\title{
Obituary
}

\section{Dr Abdul Jawad Sheikh}

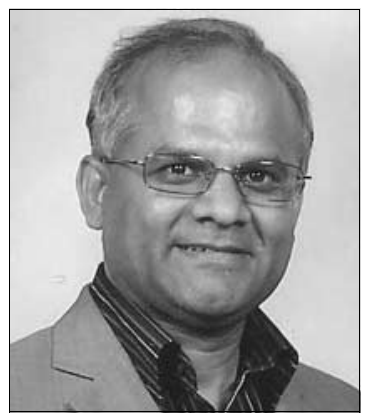

Formerly Consultant Psychiatrist, Birmingham and Solihull Mental Health National Health Service Trust

Jawad was born in Pakistan on 30 September 1954. He studied medicine at the University of Karachi and qualified MBBS as a doctor in 1978. After completing his house jobs in Pakistan, he moved to England in 1982 to begin a career in psychiatry. He started his career in the UK as a senior house officer in Harlow before joining the rotational training scheme in Nottingham from December 1983 to July 1986. He then moved to Birmingham where he completed his training.

He obtained the DPM in 1986, the MSc from the University of Birmingham in 1986 and the MRCPsych in 1987. He was appointed a consultant in Solihull in 1991 and an Honorary Senior Clinical Lecturer at the University of Birmingham in 1997. In 2000 he was appointed Medical Director of Solihull Healthcare NHS Trust, leading up to the merger with South Birmingham Mental Health Trust. He liked to take on new responsibilities and these included working as a member of the Parole Board and as a clinical advisor for the Healthcare Commission. He also worked for the mental health review tribunal and as an examiner for the Royal College of Psychiatrists.

Jawad had an interest in mixed marriages, which was no doubt prompted by his own marriage to Maria in 1984 (Maria was born in England and is of Polish descent and a Roman Catholic). He had many interests outside psychiatry: he enjoyed spending time with his family and friends, and going to the theatre. He read widely and loved sports, particularly cricket, following the fortunes of Pakistan cricket very closely. Patients and colleagues alike appreciated his natural warmth, enthusiasm and good humour.

Tragically, he developed cancer and during his year-long illness he reacted with characteristic determination and resilience, even returning to work for a period while continuing with chemotherapy.

He died on 21 July 2008. He leaves behind him his wife, Maria, and their two daughters, Katrina and Anneka.

Prakash Naik Richard Pether

doi: $10.1192 / p b . b p .10 .029397$

\section{Review}

\section{ADHD: The Essential Guide}

By Diane Paul

Need 2 Know Books, 2008, £8.99 pb, 136 pp. ISBN 9781861440600

Following the publication of the National Institute for Health and Clinical Excellence attention-deficit hyperactivity disorder (ADHD) clinical guideline in September 2008, there has been renewed interest and increased awareness about the disorder.

ADHD: The Essential Guide is intended to be an easy-toread resource for parents, teachers and carers to guide them through the process of diagnosis and treatment. There is certainly room in the market for an up-to-date guide. The book is presented in a very readable and attractive format, with some good chapters such as 'Signs and Symptoms' and 'Support from Your School', as well as sensible 'Action Points' for parents. Probably the high points of the book are the help list, references and book list.

I read with interest in the introduction that the author did not receive advice or comments on this draft from clinicians working in the field other than collaboration with a nutritional therapist. This is sadly reflected in the numerous errors throughout the book, from the inaccurate definitions of coexisting conditions (such as referring to affective disorders as inability to control emotions and exploding with angry outbursts), through to worrying confusion about the different formulations, indications and side-effects of methylphenidate and dexamfetamine. The author states incorrectly that Adderall is available in the UK and is more effective than methylphenidate. Incredibly, the author also informs us that Ritalin SR, which is not licensed in the UK, can be obtained by giving your prescription to the pharmacist who will fax it to the manufacturer. There is also inaccurate information about the roles of clinicians in child and adolescent mental health services, referral processes and assessments.

It remains unfortunate that the overwhelming number of inaccuracies completely marred a book that was clearly well intentioned by the author. She conveyed a passion in trying to produce this guide, but sadly her lack of clinical knowledge is reflected in the glaring errors throughout the book. Rather than guiding parents in the quest to seek help for their children, I fear this book will perplex them and lead to conflict with services. Until these errors are rectified, I do not feel I could recommend this book.

Karen Bretherton Child and adolescent mental health service, Leicestershire Partnership NHS Trust, email: karen.bretherton@leicspart.nhs.uk

doi: $10.1192 /$ pb.bp.08.023614 